\title{
How Greenland melts
}

\author{
M.R. van den Broeke \\ Institute for Marine and Atmospheric research, Utrecht University, PO Box 8005, \\ 3508 TA Utrecht, The Netherlands
}

\begin{abstract}
Satellite altimetry and gravimetry show that the Greenland ice sheet has been losing volume and mass since the beginning of this century. However, from these short time series of direct measurements we cannot infer what the causes of the mass loss are, i.e. ice dynamics or surface processes, or that maybe the ice sheet returns to normal after a period of volume increase and mass gain. By modelling and observing the individual components of the ice sheet mass balance, i.e. snowfall, meltwater runoff and iceberg production, we are able to identify the processes that led to the recent mass loss. We conclude that the Greenland ice sheet is significantly out of balance. Acceleration of outlet glaciers and increased runoff have contributed equally to recent Greenland mass loss. The potential for mass loss by surface processes, however, was three times greater than actually observed, due to refreezing and enhanced snowfall.
\end{abstract}

\section{Introduction}

Satellite measurements from the Gravity Recovery And Climate Experiment (GRACE) mission have revolutionized Greenland mass balance research by proving beyond a doubt that the Greenland ice sheet (GrIS) loses mass, and contributes significantly to ongoing sea level rise (SLR) [1,2]. In Greenland, GRACE data show that the mass loss is concentrated along the ice sheet margins and is progressing towards the northwest [3]. The mass loss is caused by outlet glacier acceleration [4-6] as well as enhanced runoff from the widening ablation zone, following recent atmospheric warming over the ice sheet [7].

Unfortunately, direct observations of mass changes from GRACE do not discriminate between mass losses caused by ice dynamics or surface processes. Can satellite altimetry help? Accurate, high-resolution (in the along-track direction) laser altimetry observations from ICESat show that pronounced thinning in the order of one or more metres per year occurs on the fast flowing parts of nearly all the marine-terminating outlet glaciers in Greenland [8]. This suggests that ice dynamics are responsible for an important part of the mass losses, and that warming ocean waters are, at least partly, driving these changes [9]. Superimposed are smaller yet widespread elevation changes over much larger areas $[10,11]$, caused by temporal variability in snow accumulation and firn densification [12]. Although smaller than the rapid thinning of glaciers, these widespread signals are often very significant for total ice sheet mass balance because of the much larger area they represent.

To convert volume changes, as measured by satellite altimetry, to mass changes requires knowledge of the density at which the elevation change takes place. If a glacier is thinning far below the surface, the change is of ice-dynamical nature (faster ice deformation or enhanced sliding) and the density at which the volume loss occurs is that of ice $\left(\sim 900 \mathrm{~kg} \mathrm{~m}^{-3}\right)$. If elevation changes occur in the firn layer that covers the glacier, for instance owing to changes in the firn densification rate or

This is an Open Access article distributed under the terms of the Creative Commons Attribution-Noncommercial License 3.0, which permits unrestricted use, distribution, and reproduction in any noncommercial medium, provided the original work is properly cited. 
accumulation variability, the density at which the volume loss occurs can be anything between typical values for surface snow $\left(\sim 300 \mathrm{~kg} \mathrm{~m}^{-3}\right)$ and that of ice. The density problem represents one of the major uncertainties in altimetry, another one being the unknown penetration depth of radar altimeters in firn [13].

\section{The mass budget method}

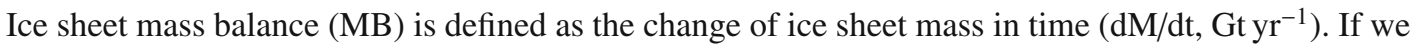
neglect basal melting of grounded ice and assume that migration of the grounding line is accounted for, MB is governed by the difference between surface mass balance (SMB) and ice discharge across the grounding line (D):

$$
M B=d M / d t=S M B-D
$$

In turn, the surface mass balance (SMB, $\left.\mathrm{Gt} \mathrm{yr}^{-1}\right)$ sums all mass fluxes towards and away from the ice sheet surface, i.e. accumulation by precipitation (snow and rain), and ablation by runoff and sublimation (including snowdrift sublimation but neglecting snowdrift erosion/deposition, which is thought to be small when integrated over the ice sheet):

$$
\text { SMB }=\text { Snow }+ \text { Rain }- \text { Sublimation }- \text { Runoff }
$$

Finally, runoff is determined by the liquid water balance (LWB, $\mathrm{Gt} \mathrm{yr}^{-1}$ ), which sums all sources (water vapour condensation, rainfall and melt) and sinks (refreezing and capillary retention) of liquid water:

$$
\text { Runoff = Condensation }+ \text { Rain }+ \text { Melt }- \text { Refreezing }- \text { Retention }
$$

The only way to separate the role of surface and ice dynamical processes in the mass loss of the GrIS is to quantify the individual components of MB, SMB and LWB: the mass budget method. The mass budget method is elaborate, as it relies on separately quantifying all surface mass fluxes as well as iceberg production, both of which are prone to uncertainties.

\section{Application to the GrIS}

Solid ice discharge is quantified from ice flow velocity and the thickness of outlet glaciers. Ice flow velocity can be accurately determined using speckle tracking from satellite radar interferometry $[14,15]$. Combined with ice thickness observations [16], the flux of solid ice can be determined within $\sim 10 \%$ accuracy. Surface mass balance (SMB) can be quantified in two different ways: by interpolation of in situ SMB observations [17,18] or from regional climate models [19,20]. Figure 1 shows an example of a modelled SMB field for the GrIS, combined with 500 in situ SMB observations and averaged for the period 1958-2008 [20]. The correlation between modelled and observed SMB is very high, especially if only observations are selected that cover a period that overlap with the model period $(\mathrm{N}=265, \mathrm{r}=0.95)$.

Note that large spatial contrasts exist: coastal southeast Greenland shows accumulation rates in excess of $3000 \mathrm{~kg} \mathrm{~m}^{-2} \mathrm{yr}^{-1}$, while northeast Greenland receives less than $100 \mathrm{~kg} \mathrm{~m}^{-2}, \mathrm{yr}^{-1}$. Due to summertime melt and runoff, the GrIS has a well-defined marginal ablation zone. The ablation zone is more then $100 \mathrm{~km}$ wide in the southwest, where ablation in excess of $3000 \mathrm{~kg} \mathrm{~m}^{-2} \mathrm{yr}^{-1}$ occurs. Because observations are sparse in high-accumulation/high ablation areas, compilations that rely purely on interpolation of available observations tend to under/overestimate SMB in these regions.

Because GRACE directly measures ice sheet mass, comparing SMB-D with GRACE requires time-integration of Eq. (1), i.e. calculation of the time-integrated (cumulative) SMB and D anomalies [21]. Because the integration constant (reference ice sheet mass $\mathbf{M}_{0}$, see Fig. 2) is unknown, the GRACE curve depicting $M(t)$ has an unknown offset, which in theory means that the present negative trend measured by GRACE could represent a return to normal conditions, following a period of mass increase that went unnoticed before GRACE was launched (green line in Fig. 2). Alternatively, 


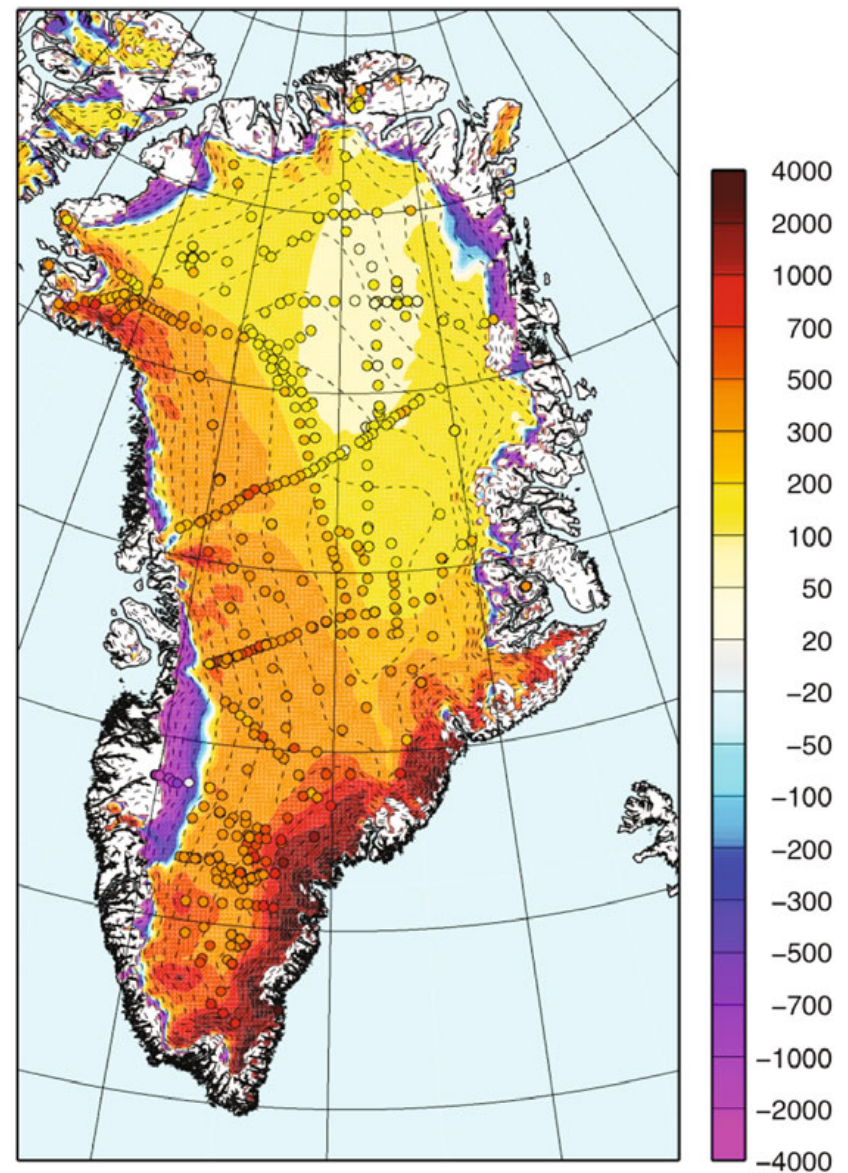

Fig. 1. Modelled and observed SMB (circles, same colour scale), in $\mathrm{kg} \mathrm{m}^{-2}$ year ${ }^{-1}$. From [20].

the ice sheet could be out of balance (red line in Fig. 2). Because $\mathrm{M}_{0}$ is not known, neither of these scenarios can be rejected based on the short GRACE time series. This also means that it is allowed to vertically shift GRACE mass time series, e.g. for visual clarity when comparing it to other methods (see Fig. 3).

Following recent work [15,21] we use 1961-1990 as a reference period during which we assume that the GrIS was in approximate balance. Using monthly GrIS SMB components from [20] we obtain a reference SMB of $480 \mathrm{Gt} \mathrm{yr}^{-1}$, considerably more than values used in previous studies $\left(\sim 300 \mathrm{Gt} \mathrm{yr}^{-1}\right)$ but confirmed by recent estimates of total GrIS discharge [15]. Using furthermore annual estimates of D from [22], a time series of SMB-D anomalies can be constructed. Because no discharge data are available before 1992, we focus on the period 1992-2008 (Fig. 3). The mass anomaly due to discharge (green line) is smooth, because we only have a single data point each year for the years 1992, 1996, 2000, 2004, 2005, 2006, 2007 and 2008, linearly interpolating for missing years and assuming changes in $\mathrm{D}$ to be slow.

The cumulative mass loss due to increased iceberg production at the end of 2008 was $\sim 700 \mathrm{Gt}$, equivalent to almost $2 \mathrm{~mm}$ global SLR. The mass anomaly due to surface processes (SMB, blue line) shows a pronounced annual cycle, following the seasonality in runoff: in summer, runoff exceeds the annual average, increasing the cumulative runoff anomaly and decreasing the SMB anomaly; in winter, the opposite happens. If the ice sheet were in balance, this saw-tooth shaped runoff/SMB time series would centre approximately around the zero line in Fig. 3, which is the case until about 2001. After that, the cumulative SMB anomaly becomes significantly negative to reach a mass loss of $\sim 700 \mathrm{Gt}$ at the end of 2008. We conclude that ice dynamics and surface processes are equally important in 


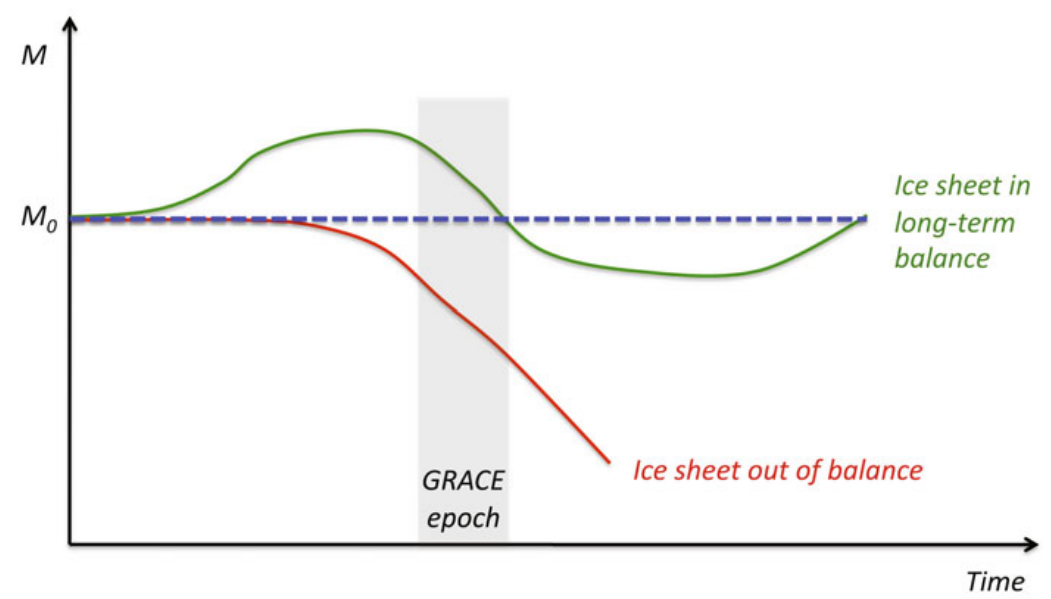

Fig. 2. Schematic GRACE mass curves for scenarios in which the ice sheet is in (long-term) balance (green line), and out of balance (red line).

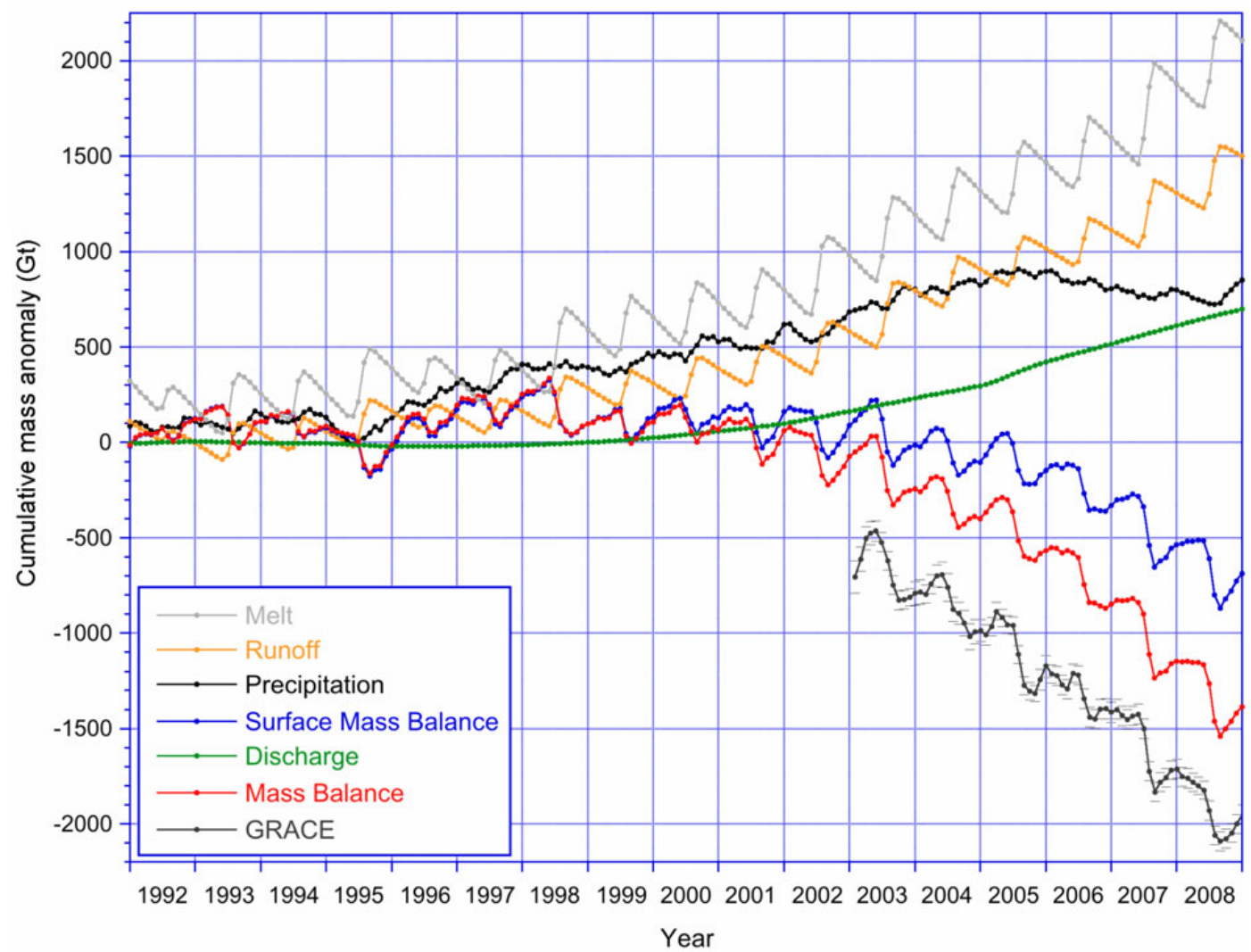

Fig. 3. Cumulative mass anomalies (Gt) of major LWB, SMB and MB components, relative to 1961-1990, adjusted from [21]. GRACE data for 2003-2008 are from [2].

explaining GrIS mass loss since 1992. Subtracting D from SMB gives the cumulative MB anomaly (red line), which can be directly compared to GRACE (black line). Excellent agreement is found $(\mathrm{r}=0.99)$, both in the amplitude of the seasonal cycle, as well as in the magnitude of the trend, which supports the use of modelled SMB fields in ice sheet mass balance research. 
Figure 3 shows cumulative anomalies of melt, runoff and precipitation. A positive melt anomaly starts to develop in the early 1990s, significantly earlier than the negative SMB anomaly. The reason for this delay is twofold: first, the melt increase occurs primarily higher on the GrIS, and most meltwater refreezes in the cold snowpack. Secondly, when the cumulative runoff anomaly finally starts to increase in the mid-to-late 1990s, the precipitation increased simultaneously, keeping the SMB anomaly around zero. Only when the precipitation anomaly levels off after 2004, does the SMB anomaly quickly become negative. Without these moderating effects of refreezing and precipitation, the 19922008 cumulative SMB anomaly would have been similar to the melt anomaly, i.e. $\sim 2100 \mathrm{Gt}$, triple the value that actually occurred and also triple the mass anomaly due to glacier acceleration. Together with the discharge anomaly, this would have led to a 1992-2008 cumulative mass loss for the GrIS of $2800 \mathrm{Gt}$, double the value that actually occurred.

\section{Conclusions}

The mass balance of the Greenland ice sheet (GrIS) can be quantified at sub-annual resolution using regional climate modelling for surface processes and satellite interferometry for solid ice discharge. Direct gravity measurements from the GRACE mission are used to validate/calibrate the results. No such calibration was necessary here. During the period 1992-2008, the acceleration of marine terminating outlet glaciers has led to a cumulative mass loss of $700 \mathrm{Gt}$. Melting started to increase in the early 1990s, but owing to enhanced refreezing and simultaneously increasing precipitation, surface mass losses were delayed. Only when precipitation returned to normal in 2004 did surface mass losses become evident. Without the moderating effects of refreezing and above-normal precipitation, the total GrIS mass loss since 1992 would have been twice the amount that actually occurred. Given that the surface melt anomalies started before glacier acceleration, there might be a connection between the two. Finally, based on the trajectory of the mass balance curve in Fig. 3 (red line), we conclude that the curve in Fig. 2 in which the GrIS is significantly out of balance represents the most likely scenario of recent Greenland mass loss.

\section{References}

1. B. Wouters, D. Chambers, E.J.O. Schrama, GRACE observes small-scale mass loss in Greenland, Geophys. Res. Lett. 35, L20501, doi:10.1029/2008GL034816 (2008)

2. I. Velicogna, Increasing rates of ice mass loss from the Greenland and Antarctic ice sheets revealed by GRACE, Geophys. Res. Lett. 36, L19503, doi:10.1029/2009GL040222 (2009)

3. S. A. Khan, J. Wahr, M. Bevis, I. Velicogna, E. Kendrick , 2010, Spread of ice mass loss into northwest Greenland observed by GRACE and GPS, Geophys. Res. Lett. 37, L06501, doi:10.1029/ 2010GL042460 (2010)

4. I. Joughin, I.W. Abdalati, M. Fahnestock, Large fluctuations in speed on Greenland's Jakobshavn Isbrae glacier, Nature 432, 608-610 (2004)

5. I.M. Howat, I. Joughin, S. Tulaczyk, S. Gogineni, Rapid retreat and acceleration of Helheim Glacier, east Greenland, Geophys. Res. Lett. 32, L22502, doi:10.1029/2005GL024737 (2005)

6. I.M. Howat, I. Joughin, T. Scambos, Rapid changes in ice discharge from Greenland outlet glaciers, Science 315, DOI: 10.1126/science.1138478, 1559 (2007)

7. E.Hanna, P. Huybrechts, K. Steffen, J. Cappelen, R. Huff, C. Shuman, T. Irvine-Fynn, S. Wise, M. Griffiths, ncreased Runoff from Melt from the Greenland Ice Sheet: A Response to Global Warming, J. Climate 21, 331-341 (2008)

8. H.D. Pritchard, R.J. Arthern, D.G. Vaughan, L.A. Edwards, Extensive dynamic thinning on the margins of the Greenland and Antarctic ice sheets, Nature 461, 971-975 (2009)

9. D.M. Holland, R.H. Thomas, B. de Young, M.H. Ribergaard, B. Lyberth, Acceleration of Jakobshavn Isbræ triggered by warm subsurface ocean waters, Nature Geosc. 1, 659-664 (2008)

10. H.J. Zwally, M.B. Giovinetto, J. Li, H.G. Cornejo, M.A. Beckley, A.C. Brenner, J.L. Saba, D. Yi, Mass changes of the Greenland and Antarctic ice sheets and shelves and contributions to sea-level rise: 1992-2002, J. Glaciol. 51, 509-527 (2005) 
11. D.C. Slobbe, P. Ditmar, R.C. Lindenbergh, Estimating the rates of mass change, ice volume change and snow volume change in Greenland from ICESat and GRACE data, Geophys. J. Int. 176, 95-106 (2009)

12. J.R. McConnell, R.J. Arthern, E. Mosley-Thompson, C.H. Davis, R.C. Bales, R. Thomas, J.F. Burkhart, J.D. Kyne, Changes in Greenland ice sheet elevation attributed primarily to snow accumulation variability, Nature 406, 877-879 (2000)

13. R. Thomas, C. Davis, E. Frederick, W. Krabill, Y. Li, S. Manizade, C. Martin, A comparison of GrIS volume changes derived from altimetry measurements, J. Glaciol. 54, 203-212 (2008)

14. E. Rignot, P. Kanagaratnam, Changes in the velocity structure of the Greenland ice sheet, Science 311, 986-990 (2006)

15. E.Rignot, J.E. Box, E. Burgess, E. Hanna, 2008, Mass balance of the Greenland ice sheet from 1958 to 2007, Geophys. Res. Lett. 35, L20502, doi:10.1029/2008GL035417

16. J.L. Bamber, S. Ekholm, W.B. Krabill, A new, high-resolution digital elevation model of Greenland fully validated with airborne altimeter data, J. Geophys. Res. 106, 6733-6745 (2001)

17. R.C. Bales, Q. Guo, D. Shen, J.R. McConnell, G. Du, J.F. Burkhart, V.B. Spikes, E. Hanna, J. Cappelen, Annual accumulation for Greenland updated using ice core data developed during 2000-2006 and analysis of daily coastal meteorological data, J. Geophys. Res. 114, D06116, doi:10.1029/2008JD011208 (2009)

18. E.W. Burgess, R.R. Forster, J.E. Box, L.C. Smith, D.H. Bromwich, Greenland ice sheet annuallyresolved accumulation rates (1958-2007), a spatially calibrated model, J. Geophys. Res. 115, F02004, doi:10.1029/2009JF001293 (2010)

19. X. Fettweis, Reconstruction of the 1979-2006 Greenland ice sheet surface mass balance using the regional climate model MAR, The Cryosphere 1, 21-40 (2007)

20. J. Ettema, M.R. van den Broeke, E. van Meijgaard, W.J. van de Berg, J.L. Bamber, J.E. Box, R.C. Bales, Higher surface mass balance of the Greenland ice sheet revealed by high-resolution climate modeling, Geophys. Res. Lett. 36, L12501, doi:10.1029/2009GL038110 (2009)

21. M.R. van den Broeke, J. Bamber, J. Ettema, E. Rignot, E. Schrama, W.J. van de Berg, E. van Meijgaard, I. Velicogna, B. Wouters, Partitioning recent Greenland mass loss, Science 326, 984-986 (2009)

22. E. Rignot, I. Velicogna, M.R. van den Broeke, A.J. Monaghan, Acceleration of the contributions of the Greenland and Antarctic ice sheets to sea level rise, Nature Geoscience submitted 